\title{
Agricultural Growth and Regional Disparity in India: A Convergence Analysis
}

\author{
Arpita Banerjee $^{\dagger 1}$ and Pravat Kumar Kuri ${ }^{2}$
}

\begin{abstract}
The deceleration in growth trends in agricultural output and yield rate is a matter of great concern in recent years in India. This study makes an attempt to examine the growth performances of agricultural production and productivity of major States of India and the nature and extent of disparity in the performances of agriculture. The growth performances have been analyzed considering three distinct phases of agricultural development in India viz the first phase of green revolution 1970-71 to 1979-80, second phase of green revolution 1980-81 to 1990-91, and the period after economic reform 1991-92 to 2007-08). The agricultural infrastructural index, constructed using Principle Component Analysis, reveals the prevalence of a wide inter-state variation in agricultural infrastructure in India. Moreover, using Generalized Method of Moments (GMM) under the panel data framework, the study attempts to examine the trends of convergence/divergence of per capita value of agricultural output over the period 1970-71 to 2007-08. The results of conditional convergence establish the argument that variations in the provision of agricultural infrastructure and natural factor like rainfall play the divergent role in accruing benefits from agriculture in India. The skewed distribution of public and private investment in favour of agriculturally developed states has been found to be responsible for enhancing the disparity in agricultural infrastructure and thus, to the per capita net state domestic product across states in India.
\end{abstract}

\section{Introduction}

The attainment of self sufficiency in foodgrain was one of the most important objectives during 70's and 80's in the history of Indian agriculture. A significant acceleration in growth of output and productivity was observed

1 Assistant Professor, M.U.C Women's College, and ${ }^{2}$ Associate Professor, Department of Economics, Burdwan University, Burdwan, West Bengal.

Corresponding author, email: econarpita@rediffmail.com 
in agriculture in India during 80's. However, the gains from productivity have been uneven across regions in the country. In India the gains from improved productivity in agriculture have not been translated into significant higher levels of economic development especially in rural areas. Moreover, during 90 's, in the reform era, situation still deteriorated leading to substantial deceleration in agricultural output and productivity. The deceleration in agricultural production affected the rural poor adversely increasing inequality further. Several factors have been pointed out for the unevenness and deceleration in agricultural development. They are variability in weather condition across regions, varied agro-climatic factors, varying levels of resource base, irrigation facility and varied infrastructural development across regions and high population pressure in rural areas. The important question is to what extent the above factors are responsible for creating divergence in agricultural development.

There is a plethora of literature about the growth, instability, cropping pattern and interstate difference in agriculture in India. Several studies such as Rao (1975), Mehra (1981), Desai and Hazell, 1982, etc. have pointed out that the new strategy of agricultural production based on High Yielding Varieties (HYV) seed fertilizer technology has contributed to the growth in production and productivity in India. In an in-depth study, Bhalla and Singh (2009) showed that a marked acceleration took place in both the output and yield growth rate in agriculture during 1980-83 to 1992-95. This result was supported by many authors like Sawant and Achuthan (1995) claiming that the yield rate of both food grain and non-food grain crops accelerated significantly along with output growth during 80's. However, these studies also observed marked deceleration in the level and trend growth rate of output and yield during 90's.Several attempts have been made in the literature to identify the factors causing the deceleration trends in agricultural growth in India. About convergence/ divergence of agricultural growth across Indian states, the study by Kalirajan et al. (1998) found the long term divergence and cyclical pattern in agricultural growth. Ghosh (2006) also found absolute divergence and conditional convergence in agricultural growth in India.

Under this backdrop, this study analyses the trend and disparity in the rate of growth of value of output and yield in agriculture in India since1970's with explicit focuses on the phases of green revolution and new economic reform. The study also focuses on the nature of convergence/divergence in the growth rate of the per capita value of agricultural output of Indian states for identifying the factors that are responsible behind the disparity in agricultural performances in India.

This paper is divided into four sections. Section 2 deals with data sources and methodology used in this study. Section 3 discusses the results 
obtained in this study in respect of growth rates, construction of agricultural indices and the convergence results obtained. Section 4 presents the concluding remarks.

\section{Data Sources and Methods}

\section{Data Sources}

The period of the study covers 38 years period from 1970-71 to 200708. Twenty major states have been studied for interstate comparisons. The study uses exclusively the secondary data. The state-wise and crop-wise value of output for the period 1970-71 to 2005-06 have been taken from various issues of National Account Statistics of the Central Statistical Organisation of the Govt of India.. The figure for value of agricultural output of Indian states has been converted at constant price 1999-2000. The state-wise data on inputs and operated area for different years are collected from different issues of Indian Agriculture in Brief, Directorate of Economics and Statistics, Ministry of Agriculture and Centre for Monitoring Indian Economy, Agriculture. The data for area, yield and production of selected crop for India and the states are collected from different issues of Centre for Monitoring Indian Economy, Agriculture. The data for per capita capital expenditure during 1980-81 to 2009-10 has been collected from "Handbook of Statistics on State Government Finance" by Reserve Bank of India, 2010. The statistic for private investment i.e., loans extended by AIFI has been taken from various issues of the "The IDBI Report on Development Banking" in India. The time series data for PCNSDP has been collected from 'Domestic Product of states in India 1960-61 to 2006-07', EPW Research foundation (2009) and from various issues of Central Statistical Organization, National Account Statistics, Ministry of Statistics and Programme Implementation, Government of India.

\section{Methodology}

The statistical and econometric methodologies those have been followed in this study can be summarized under three headings relating to the estimation of growth, construction of agriculture infrastructure index and convergence analysis in dynamic panel data framework.

\section{Growth Estimation}

For consumption of growth rates of value of agricultural output and productivity the trend growth rates have been computed. The equation used for computing exponential growth rates is $\ln Y_{l}=a+b t+u_{t}$ Where $Y_{t}$ is the index of agricultural output or productivity, a is constant and $t$ is the time in 
years and the $u_{t}$ is the error term. The estimates of the coefficient $\mathrm{b}$ are taken as estimates of annual exponential growth.

For measuring the growth rate in pre-reform period the kinked exponential growth rates have been computed. The equation for kinked exponential growth rate with a single kink is $\ln Y_{t=} a+b_{1} D_{1} t+b_{2} D_{2} t+u t$ (Boyce, 1987).

\section{Construction of Composite Index of Agricultural Infrastructure (CIAI)}

For measuring disparity among the states in respect of agricultural infrastructural indicators, a composite index has been computed. The Composite Index of Agricultural Infrastructure is computed by using deprivation method. Eight indicators relating to agricultural development have been chosen to construct the index. The steps taken for computation of the index are follows.

1) The component indices are constructed by using the formula $I_{i j}=\left(X_{i j}-\right.$ $\left.\min X_{i j}\right) /\left(\max X_{i j}-\min X_{i j}\right)$,Where $I i j=$ component index for the $j^{\text {th }}$ state with respect to the $I^{\text {th }}$ indicator. $X i j=$ actual value of the $j^{\text {th }}$ state in the $i^{\text {th }}$ variable. $\operatorname{Min} X_{i j}$ and $\operatorname{Max} X^{i j}$ are minimum and maximum values of the $i^{\text {th }}$ indicator.

2) Using Principal Component Analysis weights of each indicator are determined.

3) Finally, the CIAI is computed using the formula $C I A I_{j}$ $=\sum_{i=1}^{n} w i I i j / \sum_{i=1}^{n} w i$, Where $w i=$ weight attached to $i^{\text {th }}$ indicator, $C I A I_{j}=$ the index of the $j^{\text {th }}$ state.

\section{Convergence Analysis in Cross Section and Panel Data Framework}

According to Barro and Salai- Martin there are two notions of convergence, $\sigma$ convergence and $\beta$ convergence. $\sigma$ convergence measure the behaviour of cross sectioanal dispersion of a particular variable overtime, Whereas $\beta$ convergence (absolute) examines whether the low growth states would be able to grow at a faster rate than the richer one and thereby catch up the richer states. [Barro and Sala-i-Martin, 1991,1992,1995]. Conditional $\beta$ convergence is perceptible only after other factors that may cause variation in steady states across regions are accounted for (Ghosh, 2006). In this paper ,the panel data specification has been used to examine the conditional convergence of PCVOA. Here the Generalised method of moments estimation technique has been used. GMM estimation technique overcomes the twin problems of correlation between the explanatory variable and endogeneity. The method of GMM is to take the first difference of the basic growth 
equation to eliminate the fixed regional effects and then use instrumental variables estimation to address the correlation between the differenced lagged dependent variable and the included first order moving average error term (Arellano and Bond, 1991).

\section{Results and Discussion}

\section{Growth Performance of Indian States in Agriculture}

The growth performance of the states has been analyzed considering three distinct phases of agricultural development in India viz the first phase of green revolution 1970-71 to 1979-80, second phase of green revolution 198081 to 1990-91, and the period after economic reform 1991-92 to 2007-08). The exponential growth ${ }^{2}$ rates of value of output and productivity for the country during the whole period (1970-71 to 2005-06) revealed that all India agricultural output and yield grew at the rate of $2.6 \%$ and $1.43 \%$ respectively. The states like Haryana (3.46\%), Madhya Pradesh (3.38), Rajasthan (3.36\%), Goa (3.3\%) and West Bengal (3.24\%) achieved higher growth in the level of output whereas the states like Madhya Pradesh (2.81\%), Rajasthan (2.5\%), Haryana (2.5\%), Punjab (2.12\%) and Uttar Pradesh (2.04\%) registered higher growth in productivity during the entire period. The performance of the state of Jammu and Kashmir remained poor in both respects during the whole period. The study revealed that the performance of the Indian agriculture during the first phase of green revolution (1970-71 to 1979-80) was not extraordinary. All India growth for the agricultural output and yield during this period was recorded as $1.88 \%$ and $1.48 \%$ per annum respectively. However, during this time period few states achieved outstanding growth in the rete of output and yield. In the level of output, the states like Manipur (6.46\%), Arunachal Pradesh (5.9\%), Maharashtra (5.78\%), Punjab (5.43\%) and Haryana $(3.36 \%)$ performed significantly well, whereas in case of yield the states Punjab, Maharashtra, Manipur achieved significant growth. In fact, during this period the effect of green revolution was not widespread all over the country. This is evident from the observed lower growth rate of other states like Andhra Pradesh, Madhya Pradesh, Kerala, Rajasthan, Orissa, Bihar, Karnataka and Jammu and Kashmir in both output and yield. The effect of green revolution was visible from the second phase of green revolution, form the period 1980-81 to 1990-91. It has been observed from the kinked exponential growth rate (see Table 1 and Table 2) that all India agricultural performance registered an unprecedented improvement in both output and yield growth during the second phase of green revolution. The

\footnotetext{
${ }^{2}$ In $Y_{t}=a+b_{t}+u_{t}$ (Semi logarithmic equation is estimated to derive the exponential growth rate).
} 
kinked exponential growth rate of value of output and yield for India were $3.34 \%$ and $3.38 \%$ per annum respectively during this period. Most of the states grew at an accelerated rate in both output and yield during this period. The states such as Tamil Nadu (5.46\%), West Bengal (5.25\%), Rajasthan (5.5\%), Punjab (4.9\%), Haryana (4.78\%) and Madhya Pradesh (4.62\%) achieved outstanding growth in agricultural output and the states of Punjab (6.38), Haryana (6.29), Madhya Pradesh (6.11) and West Bengal (5.48) achieved remarkable growth in yield rate. Moreover, during this period the states of different regions i.e, West Bengal of eastern region, Rajasthan of central region, Tamil Nadu of Southern region contributed to the higher Growth rate in India. Most other states except a few registered higher growth compared to the previous period during the second period.

Table1: $\quad$ Trend growth rate of value of output of agriculture during 1970-71 to 2005-06 of Indian states

\begin{tabular}{|c|c|c|c|c|}
\hline \multirow{3}{*}{ Growth rate } & \multicolumn{2}{|c|}{ Exponential Growth rate } & \multicolumn{2}{|c|}{ Kinked exponential growth rate } \\
\hline & $\begin{array}{l}\text { Whole period } \\
\text { (1970-71 to 2005-06) }\end{array}$ & $\begin{array}{l}\text { 1st sub-period } \\
1970-71 \text { to 1979- } \\
80\end{array}$ & $\begin{array}{l}\text { 2nd sub-period } \\
1980-81 \text { to1990- } \\
91\end{array}$ & $\begin{array}{l}\text { 3rd sub-period } \\
\text { 1990-91to2005- } \\
06\end{array}$ \\
\hline & & & b1 & b2 \\
\hline Andhra Pradesh & 2.406 & 1.93 & 3.16 & 1.46 \\
\hline Arunachal Pradesh & 1.065 & 5.9 & 3.87 & 2.32 \\
\hline Assam & 2.098 & 1.67 & 2.63 & 1.45 \\
\hline Bihar & 2.549 & 0.61 & 2.26 & 1.98 \\
\hline Goa & 3.3 & 3.01 & 1.46 & 3.12 \\
\hline Gujarat & 2.082 & 2.76 & -0.37 & 3.29 \\
\hline Haryana & 3.463 & 3.36 & 4.78 & 2.34 \\
\hline Himachal Pradesh & 2.797 & 1.4 & 2.63 & 1.08 \\
\hline Jammu \& Kashmir & -0.263 & 1.79 & 1.75 & -0.03 \\
\hline Karnataka & 2.251 & 2.1 & 3.94 & 2.07 \\
\hline Kerala & 1.189 & -0.8 & 2.76 & 2.57 \\
\hline Madhya Pradesh & 2.76 & -0.93 & 4.61 & 1.84 \\
\hline Maharashtra & 3.38 & 5.78 & 2.2 & 3.94 \\
\hline Manipur & 2.8 & 6.46 & 0.45 & 2.16 \\
\hline Orissa & 1.57 & 0.44 & 1.66 & 0.17 \\
\hline Punjab & 2.88 & 5.43 & 4.9 & 1.47 \\
\hline Rajasthan & 3.36 & 0.83 & 5.5 & 2.58 \\
\hline Tamil Nadu & 1.896 & 1.77 & 5.46 & 0.15 \\
\hline Uttar Pradesh & 1.918 & 1.09 & 3.14 & 1.58 \\
\hline West Bengal & 3.24 & 2.26 & 5.25 & 2.09 \\
\hline Delhi & 2.054 & 1.59 & -1.9 & 1.23 \\
\hline India & 2.6 & 1.88 & 3.34 & 2.0 \\
\hline
\end{tabular}


Table 2: $\quad$ Trend growth rate of yield from agriculture during 1970-71 to 2005-06 of Indian states

\begin{tabular}{|c|c|c|c|c|}
\hline \multirow{3}{*}{ States } & \multicolumn{2}{|c|}{$\begin{array}{l}\text { Exponential } \\
\text { Growth rate }\end{array}$} & \multicolumn{2}{|c|}{$\begin{array}{l}\text { Kinked exponential growth } \\
\text { rate }\end{array}$} \\
\hline & $\begin{array}{l}\text { Whole } \\
\text { period }\end{array}$ & $\begin{array}{l}\text { 1st } \\
\text { sub- } \\
\text { period }\end{array}$ & $\begin{array}{l}\text { 2nd sub- } \\
\text { period }\end{array}$ & 3rd sub-period \\
\hline & $\begin{array}{l}1970 \text { to } \\
2006\end{array}$ & $\begin{array}{l}1970-- \\
1980\end{array}$ & $\begin{array}{l}1980- \\
1991\end{array}$ & $\begin{array}{l}1991-92 \text { to } \\
2008-09\end{array}$ \\
\hline Andhra Pradesh & 1.87 & 2.56 & 2.64 & 1.56 \\
\hline Assam & 0.4 & -0.37 & 2.98 & 0.021 \\
\hline Bihar & 1.91 & -0.0005 & 3.86 & 1.24 \\
\hline Gujarat & 1.35 & 2.26 & -0.34 & 2.93 \\
\hline Haryana & 2.5 & 2.5 & 6.25 & 0.19 \\
\hline Himachal Pradesh & 0.27 & 1.053 & 4.46 & -0.34 \\
\hline Jammu \& Kashmir & -2.79 & 0.69 & 2.08 & -1.22 \\
\hline Karnataka & 0.82 & 2.5 & 2.73 & 2.06 \\
\hline Kerala & 0.7 & -0.62 & 3.42 & 1.58 \\
\hline Madhya Pradesh & 2.81 & -1.21 & 6.1 & 1.95 \\
\hline Maharashtra & 1.92 & 4.54 & 2.32 & 3.02 \\
\hline Manipur & 1.64 & 3.23 & 3.21 & -0.41 \\
\hline Orissa & -0.64 & -0.19 & 2.22 & -0.28 \\
\hline Punjab & 2.12 & 3.9 & 6.38 & -1.07 \\
\hline Rajasthan & 2.52 & 0.56 & 4.76 & 1.79 \\
\hline Tamil Nadu & 1.96 & 3.15 & 4.33 & 1.53 \\
\hline Uttar Pradesh & 2.04 & 0.73 & 4.71 & 0.19 \\
\hline West Bengal & 0.78 & 1.25 & 5.48 & -0.29 \\
\hline India & 1.43 & 1.48 & 3.38 & 1.16 \\
\hline
\end{tabular}

However, it has been observed from this study that the phase of outstanding growth could not be sustained till the reform period. The agricultural output and yield growth of the country experienced a severe slowdown during the post reform period. All India growth in output and yield rate declined to $2 \%$ and $1.16 \%$ per annum during this period compared to $3.34 \%$ and $3.38 \%$ in the previous period. Except the states Maharashtra, Gujarat and Goa, all the states experienced a significant deceleration in both output and yield growth in the reform period. Some states also registered negative growth during this period. In fact, according to many researchers the most important factor for this agricultural downturn may be the result of slowdown of food grain production in the post reform period in India. Since food grain comprises nearly $60 \%$ of the total crop output in India and majority of the states are dependent on production of food grain, the deceleration in food grain production is reflected in the result of growth of value of crop output. Thus, the results establish that there was a significant acceleration in growth rate in the value of output and yield during the $2^{\text {nd }}$ phase of green revolution but the post liberalization period has marked a sign of depression 
both in agricultural output and its yield rate in India. Our findings conform to the previous empirical studies by Bhalla and Singh and others. In a comprehensive study about the growth and regional disparity of Indian states in respect of agricultural output, yield and area, Bhalla and Singh (2009) argued that increase in regional disparity during the first phase of green revolution (1971-81) was followed by decline in the same during the second phase of green revolution due to the spread effect of HYV technology. However, the post liberalization period (since 1991) witnessed the continuous decline in growth rates in Indian Agriculture. This result was supported by the authors like Mathur et al., 2006, Mahendradev (1987), Janaiah et al. (2005) and Chand et al. (2007)). According to these authors the factors like the slowdown in growth of fertilizer use, declining irrigation intensity, reduction of energy use and lack in the adoption of modern techniques were considered to be attributable to the deceleration in the trends of agricultural growth in India during 90's (Mathur et al., 2006, Mahendradev (1987), Janaiah et al. (2005), Chand et al. (2007).

\section{Regional Disparity in Agricultural Infrastructure in India: An Interstate Analysis}

India is characterized by wide regional variation in agro-climatic condition. Agricultural output in different region is varied due to varied agroclimatic factors, physical resource endowment and also varying level of investment in rural infrastructure and technological innovation ${ }^{3}$. The regional variation in agricultural infrastructure and the use of agricultural inputs in India is quite high.

To provide a clear picture, a composite index of agricultural infrastructure has been constructed by 'Deprivation Method' to explore the disparity in agricultural infrastructure across the states of India ${ }^{4}$. The detailed

\footnotetext{
${ }^{3}$ Apart from these physical factors, agrarian relations and tenurial contracts play an important role in enhancing agricultural productivity and efficiency. For details see Laha and Kuri, 2012.

${ }^{4}$ For constructing this index eight agricultural development indicators are selected. They are Cropping intensity (CI), Percentage irrigated area to GCA (IAGC), Fertilizer consumption per hectare of GCA (fcgc), Credit to agriculture (CTA), Number of tractors and pump sets used per 1000 hectares (TAP), Average yield of agricultural land (AY), Road length per $100 \mathrm{sq} \mathrm{km} \mathrm{(RL),} \mathrm{Percentage} \mathrm{share} \mathrm{to} \mathrm{total}$ consumption of electricity in agriculture (CELA).
} 
methodology of constructing the index was explained in the methodology section. The result of the index and the subsequent rank of the states according to the index are presented in Table 3. From the table it is clear that there exists a widespread disparity among states in respect of the distribution of agricultural inputs in India. The advanced states consistently enjoyed the benefit of better agricultural infrastructure throughout the period under study. For example the states like Punjab, Haryana, Uttar Pradesh, Tamil Nadu and Andhra Pradesh occupied the top positions according to the rank of the index whereas the states Assam, Himachal Pradesh and Orissa lagged behind throughout the period. Assam and Orissa remained at the bottom two throughout the study period. The states like Kerala, Karnataka, Gujarat, Maharashtra, Rajasthan and West Bengal occupied middle positions during the periods under study. The states of Jammu and Kashmir deteriorated to a large extent as its position slipped from $9^{\text {th }}$ in $1980-81$ to $14^{\text {th }}$ in $2007-08$ during the whole period. The reverse is happened for Madhya Pradesh as its position improved from 16.5 in $1980-81$ to $12^{\text {th }}$ in $2007-08$ respectively. Thus from the result of composite index it can be said that wide disparity had remained in the distribution of agricultural infrastructure across states of India during the study period.

Table 3: Composite index of agriculture infrastructure of Indian states during 1980-81 to 2007-08 (CIAI)

\begin{tabular}{lcccccccc}
\hline & \multicolumn{3}{c}{ INDEX } & \multicolumn{5}{c}{ RANK } \\
\cline { 2 - 8 } & $\mathbf{1 9 8 0 - 8 1}$ & $\mathbf{1 9 9 0 - 9 1}$ & $\mathbf{2 0 0 0 - 0 1}$ & $\mathbf{2 0 0 7 - 0 8}$ & $\mathbf{1 9 8 0 - 8 1}$ & $\mathbf{1 9 9 0 - 9 1}$ & $\mathbf{2 0 0 0 - 0 1}$ & $\mathbf{2 0 0 7 - 0 8}$ \\
\hline Andhra Pradesh & 0.33 & 0.52 & 0.57 & 0.58 & 5 & 4 & 4.5 & 4 \\
Assam & 0.10 & 0.10 & 0.10 & 0.08 & 16.5 & 17 & 17 & 16 \\
Bihar & 0.21 & 0.29 & 0.39 & 0.39 & 11 & 8.5 & 8 & 8 \\
Gujarat & 0.28 & 0.31 & 0.32 & 0.45 & 7 & 7 & 10 & 6 \\
Haryana & 0.60 & 0.72 & 0.73 & 0.76 & 2 & 2 & 2 & 2 \\
Himachal Pradesh & 0.17 & 0.17 & 0.16 & 0.16 & 13.5 & 15 & 15 & 15 \\
Jammu \& Kashmir & 0.22 & 0.22 & 0.20 & 0.23 & 9 & 12.5 & 14 & 14 \\
Karnataka & 0.17 & 0.33 & 0.41 & 0.37 & 13.5 & 6 & 7 & 9 \\
Kerala & 0.31 & 0.28 & 0.33 & 0.27 & 6 & 10 & 9 & 13 \\
Madhya Pradesh & 0.10 & 0.21 & 0.22 & 0.31 & 16.5 & 14 & 13 & 12 \\
Maharashtra & 0.21 & 0.26 & 0.28 & 0.32 & 11 & 11 & 11 & 11 \\
Orissa & 0.12 & 0.13 & 0.12 & 0.07 & 15 & 16 & 16 & 17 \\
Punjab & 0.90 & 0.94 & 0.85 & 0.85 & 1 & 1 & 1 & 1 \\
Rajasthan & 0.24 & 0.22 & 0.27 & 0.34 & 8 & 12.5 & 12 & 10 \\
Tamil Nadu & 0.51 & 0.50 & 0.57 & 0.54 & 4 & 5 & 4.5 & 5 \\
Uttar Pradesh & 0.53 & 0.61 & 0.61 & 0.63 & 3 & 3 & 3 & 3 \\
West Bengal & 0.21 & 0.29 & 0.42 & 0.41 & 11 & 8.5 & 6 & 7 \\
\hline
\end{tabular}

\section{Agricultural Growth in India: A Convergence Analysis}

Several attempts have been made in India to explain the nature of convergence in agricultural growth. Kalirajan et al. (1998), found wide regional divergence in agricultural production and productivity in India. According to them, the investment climate in agriculture and operation of both the supply and demand factors are responsible for slowing down of 
growth rates and the regional divergence in agricultural production and productivity. Similarly, Ghosh (2006) in his study found absolute $\beta$ and $\sigma$ divergence in land productivity, labour productivity and per capita agricultural output across states after the dissemination of new HYV technology and large scale economic reforms. He also found conditional convergence in agricultural development taking human capital, physical capital and rural infrastructure as conditional variable. Under this backdrop, to analyze the nature of convergence/divergence in agricultural output, this study tested sigma convergence and absolute $\beta$ convergence over the period 197071 to 2007-08 for major Indian states. Using the GMM technique, conditional convergence of PCVOA has also been tested in a dynamic panel data framework.

Sigma $(\sigma)$ convergence is tested by computing the standard deviation of logarithm of Per Capita Value of Agricultural output across regions. The result is displayed in Figure 1. The standard deviation increased from 0.4 in 1970-71 to 0.53 in 2008-09. This indicates a trend of divergence. In the Figure 1 it is observed that during 1975-76 disparity increased considerably but it slowed down during 80 's i.e., in the second phase of green revolution, but from the year 1991-92 it again picked up and continued to rise till 200809. Therefore, the test of sigma convergence confirms the divergence of per capita value of agricultural output across Indian states over time.

Figure 1: $\quad$ Sigma coefficient of per capita value of agricultural output

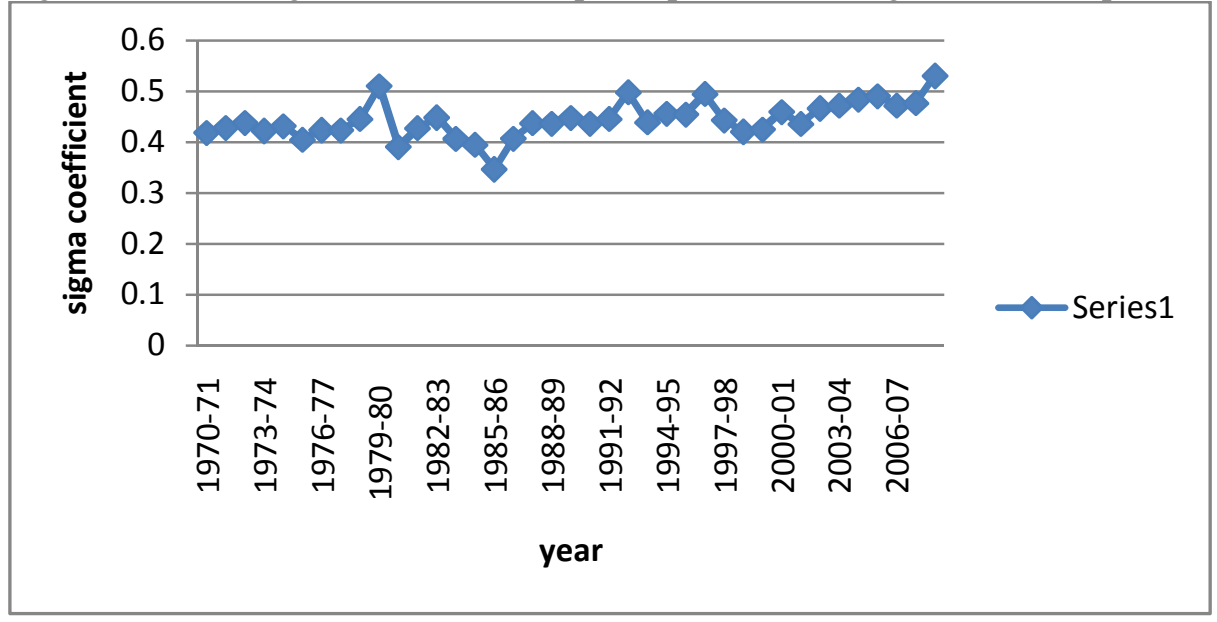

In the second step, to reaffirm the divergence in PCVOA, absolute $\beta$ convergence is tested. $\beta$ convergence is tested by regressing the growth rate of PCVOA on initial level of PCVOA. The regression equation used for this analysis is follows. 
$G i, t, t-\tau=[\ln (Y i, t)-\ln (Y i, t-\tau)] / \tau=\alpha+\beta \ln (Y i, t-\tau)+\varepsilon i, t$

Gi,t,t- $\tau$ is $i^{\text {th }}$ region's average growth rate of PCVOA between the period $t$ and $t-\tau \cdot \ln (Y i, t)$ and $\ln (Y i, t-\tau)$ are the natural logarithm of $i^{\text {th }}$ region's PCVOA at time $t$ and $t-\tau$ respectively. $\tau$ - length of the time period. Negative sign of regression coefficient implies absolute $\beta$ convergence, otherwise divergence Ghosh (2006). In this analysis, four regressions have been fittedone for whole period, other two for pre and post reform period and the last one for the last decade i.e. for the period 2000-01 to 2008-09. The result for absolute $\beta$ convergence is depicted in the Table 4 .

Table 4:

Regression result of absolute $\beta$ convergence of PCVOA

\begin{tabular}{lrrrr}
\hline Period & $\boldsymbol{\beta}$ coefficient & t-value & significance & $\mathbf{R}^{\mathbf{2}}$ \\
\hline 1970-71 to 2008-09 & $9.23 \mathrm{E}-03$ & 1.146 & 0.266 & 0.065 \\
Pre Reform Period & & & & \\
1970-71 to 1990-91 & $1.40 \mathrm{E}-02$ & 1.14 & 0.268 & 0.064 \\
post reform Period & & & & \\
1991-92 to 2008-09 & $5.68 \mathrm{E}-03$ & 2.535 & 0.02 & 0.254 \\
2000-01 to 2008-09 & $6.27 \mathrm{E}-03$ & 0.776 & 0.447 & 0.031 \\
\hline
\end{tabular}

Source: Author's calculation

The results show positive $\beta$ coefficient for the whole period and the sub-periods. This implies absolute $\beta$ divergence in PCVOA over all periods. Thus the result of both sigma and $\beta$ convergence analysis indicated a sign of divergence in agricultural performance across states in the country.

In the absence of absolute convergence of PCVOA over the period, the conditional convergence for the same has been tested for the period 198081 to $2007-08$ in a panel data framework using the GMM estimation technique. The chosen explanatory variables are the rainfall of different states, composite index of agricultural infrastructure (CIAI) and literacy rate. A panel of four years has been used. Therefore, there are 7 panels and 16 states. The total number of observation for 16 states becomes 112 and the GMM estimation method is used. The regression equation that has been fitted here is $\Delta \log \left(y_{i t}\right)=(1+\beta) \Delta \log \left(y_{i t-4}\right)+\psi \Delta X_{i t}+\Delta_{t}+\varepsilon_{i t}-\varepsilon_{i t-4}$.

The result of the conditional convergence analysis is displayed in Table 5. In the GMM estimation analysis, the coefficient of $1+\beta$ becomes 0.104 i.e. the estimated coefficient of $\beta$ is -0.896 which is significant at $10 \%$ level. This implies conditional $\beta$ convergence. It is revealed from the result that the coefficient of CIAI and the coefficient on rainfall are positive and 
highly significant. The coefficient of literacy rate is also significant but at $14 \%$ level. Thus the result implies that the variation in the provision of agricultural infrastructure across states played the dominant role in widening the gap in per capita value of agricultural output across states. It is also revealed from the result that Indian states are converging to their own steady states. Actually the states are converging to divergent steady states.

Table 5: $\quad$ Result of gmm analysis with determinant CIAI, rain and literacy rate during the period 1980-81 to 2007-08

\begin{tabular}{lrrr}
\hline Explanatory Variable & Coefficient & t-Statistic & P value \\
\hline PCVOA(-1) & 0.104089 & 1.346821 & 0.182 \\
CIAI & 1.356878 & 3.277818 & 0.0016 \\
RAIN & 0.000136 & 7.519695 & 0 \\
LIT & 0.002709 & 1.476619 & 0.1439 \\
\hline
\end{tabular}

Source: Author's calculation

Note: i) On the availability of comparable figures for the chosen variables, 16 states have been identified and compiled data over a period of 28 years 1980-81 to 2007-08.

ii) The abbreviation PCVOA stands for per capita value of agricultural output, CIAI, Composite Index of Agricultural Infrastructure, RAIN stands for rainfall and LIT Stands for Literacy rate

\section{Reasons for Divergence in PCVOA in India}

In the preceding analysis it has been observed that the crucial determinants of difference in agricultural growth across states of India are mainly agricultural infrastructure and rainfall. Moreover, several studies stated that the disproportionate distribution of government investment was one of the reasons behind the regional divergence in the agricultural infrastructure and hence growth of agricultural production in India (Kalirajan et al. (1998), Bhalla and Singh, 2009, Ghosh (2006)). This section makes an attempt to examine the role of public investment in the creation of agricultural infrastructure across the states of India. In order to infer about the distribution of public investment in agriculture across states, a variable (per capita capital expenditure by the government (PCCE)) has been taken as a proxy for public investment. PCCE has been regressed on CIAI in the fixed effect framework ${ }^{5}$. The result (see Table 6) shows a statistically significant positive relationship between the two.

\footnotetext{
${ }^{5}$ For methodology of fixed Effect Framework, see Green (2003).
} 
Table 6: $\quad$ Relation between government expenditure and agriculture infrastructure across states in India

Dependent Variable: PCCE

\begin{tabular}{lccc}
\hline Explanatory Variable & Coefficient & t-Statistic & P value \\
\hline C & 2.197639 & 3.868587 & 0.0002 \\
CIAI & 9.194107 & 6.002615 & 0.0000 \\
\hline
\end{tabular}

Note: The abbreviation PCCE stands for Per Capita Capital Expenditure made by Government, CIAI, Composite Index of Agricultural Infrastructure.

The above result implies that the distribution of public investment has been made in favour of agriculturally developed states. Again to know about the distribution of private investment in agriculture across states the variable, per capita loans sanction by the AIFI to states (PCLS) has been regressed on CIAI. Again, the positive and significant relation between the two ensures that private investment is also biased towards agriculturally developed states (see Table 7). It is natural that private investment is also generally flows to the states where returns would be high. Accordingly, making investment in already developed states would be profitable. Therefore the skewed distributions of public and private investment along with difference in weather were the possible reasons for agricultural divergence in Indian states.

Table 7: $\quad$ Relation between private expenditure and agriculture infrastructure across states in India

Dependent Variable: PCLS

\begin{tabular}{lrrr}
\hline Explanatory Variable & Coefficient & t-Statistic & P value \\
\hline C & 4.185833 & 7.27191 & 0 \\
CIAI & 4.005533 & 2.580844 & 0.0113
\end{tabular}

Note: the abbreviation PCLS stands for Per Capita Loans Sanctioned by AIFI, CIAI Composite Index of Agricultural Infrastructure.

Some recent studies by Yang and Zhu (2004) and Tiffin and Irz, 2006 find agriculture as an important cause for economic growth and conclude that economic growth cannot be sustained without improving agricultural productivity. To enquire about whether the regional difference in agricultural infrastructure has any role to play in explaining divergence in PCNSDP, PCNSDP of states is regressed on CIAI (see Table 8). 
Table 8: $\quad$ Relation between pcnsdp and agricultural infrastructure across states in India

Dependent Variable: PCVOA

\begin{tabular}{lccc}
\hline Explanatory Variable & Coefficient & t-Statistic & P value \\
\hline C & 4.657447 & 1.907901 & 0.0651 \\
CIAI & 11.85005 & 1.901838 & 0.0660
\end{tabular}

Note: The abbreviation PCVOA stands for Per Capita Value of agricultural Output and CIAI is Composite Index of Agricultural Infrastructure

It is established from regression result that PCNSDP is high where CIAI is high. This implies that a state with provision of better agricultural infrastructure can enjoy higher level of economic growth. Thus it is clear from the above results that unequal distribution of public and private investment across states was one of the most important reasons behind the regional disparity in agricultural infrastructure in India. This regional divergence in agricultural infrastructure, in turn held responsible for divergence in agricultural and economic growth in the country.

\section{Conclusion}

This study makes an attempt to examine the performance of major Indian states in the level of agricultural development and also disparity prevailing across states in terms of agricultural performance. The estimated exponential and kinked exponential growth rates of value of agricultural output and yield for three periods reveal that the outstanding and remarkable growth which was observed by Indian states during 80's has been deteriorated significantly during 90's. The construction of CIAI however shows a high degree of regional variation in agricultural infrastructures across states of India. The ranking structure of CIAI indicates that the states with developed infrastructure performed much better in growth of agricultural output and productivity in all the periods. Finally, the convergence analysis depicts the evidence of both $\sigma$ divergence and absolute $\beta$ divergence in PCVOA for the period 1980-81 to 2007-08. The result shows robust evidence of conditional $\beta$ convergence. It has been established that agricultural infrastructure across states is highly uneven in the country. Moreover, the disproportionate distributions of public and private investment in favour of agriculturally developed states are found to be responsible for wide disparity in agricultural performances in India which, in turn, is considered to be responsible for wide disparity in the per capita net state domestic product across states in India. 


\section{References}

Arellano, M. and S. Bond (1991). Some Tests of Specification for Panel Data: Monte Carlo Evidence and an Application to Employment Equations", Review of Economic Studies, 58:277-297.

Bhalla, G.S and G. Singh (2009). Economic Liberalisation and Indian Agriculture: A Statewise Analysis. Econ. Political Weekly, 46:34-44.

Barro, R.J. and X. Sala-i-Martin (1991). Convergence across States and Regions, Brookings Papers on Economic Activity, I:107-182.

Barro, R.J. and X. Sala-i-Maritn (1992). Convergence, Journal of Political Economy, 100(April):223-251.

Barro, R.J. and X. Sala-I-Martin (1995). Economic Growth, McGraw-Hill: New York.

Boyce, J.K (1987). Agrarian Impasse in Bengal: Institutional Constraints to Technical Change. Oxford University Press.

Central Statistical Organisation (1985). Statewise and Cropwise Estimates of Value of Output from Agriculture in India during 1960-61 to 198081. National Account Statistics, Ministry of Statistics and Programme Implementation, Government of India. Retrieved from $<\mathrm{http}: / /$ mospi.nic.in/mospi_cso_rept_pubn.html $>$.

Central Statistical Organisation (1996). Statewise and Cropwise Estimates of Value of Output from Agriculture in India during 1980-81 to 199091. National Account Statistics, Ministry of Statistics and Programme Implementation, Government of India. Retrieved from $<\mathrm{http}: / /$ mospi.nic.in/mospi_cso_rept_pubn.html $>$.

Central Statistical Organisation (2008). Statewise and Cropwise Estimates of Value of Output in Agriculture in India during 1990-91 to 2002-03. National Account Statistics, Ministry of Statistics and Programme Implementation. Retrieved from $<\mathrm{http}: / /$ mospi.nic.in/mospi_cso_rept_pubn.html $>$.

Centre for Monitoring Indian Economy (CMIE) (2010). Agriculture, Mumbai. Retrieved from $<$ www.cmie.com $>$. 
Chand, R, S.S Raju and L.M. Pandey (2007). Growth Crisis in Agriculture Severity and Options at National and State Level. Economic and Political Weekly, 42(26):2528-2533.

Desai, G.M. and P.B.R. Hazell (1982). Instability in Indian Foodgrain Production. International Food Policy Research Institute, Washington D.C.

EPW Research Foundation (2009). Domestic Product of States of India: 196061 to 2006-07. EPW Research Foundation, Mumbai, India. Pp: 515.

Ghosh, M. (2006). Regional Convergence in Indian Agriculture. Indian J. Agric. Eco., 61:610-629.

Ghosh, B.K. (2010a). Growth and Variability in the Production of Crops in West Bengal Agriculture. Trends in Agricultural Economics, 3:135146.

Ghosh, B.K. (2010b). Fading Glory of West Bengal Agriculture in the Context of Globalization: Need for a Change in Cropping Pattern. Trends in Agricultural Economics, 3(4):185-189.

Greene, W.H. (2003). Econometric Analysis, Fifth Edition, Pearson Education (Singapore) Pvt. Ltd., Delhi, India.

Janaiah, A., K. Otuska and M. Hossain (2005). Is the Productivity Impact of the Green Revolution in Rice Vanishing? Empirical Evidence from TFP Analysis. Econ. Political Weekly, 40:5596-5600.

Kalirajan, K.P., S. Bhid and R.T. Shand (1998). India's Agricultural Dynamics: Weak Link in Development. Econ. Political Weekly. Retrieved from <http://www.jstor.org/discover/10.2307/ 4407209 uid $=3738832$ \&uid $=2129$ \&uid $=2$ \&uid $=70$ \&uid $=4 \&$ sid $=476$ 99130041207>.

Mahendradev, S. (1987). Growth and Instability in Foodgrains Production: An Inter-state Analysis. Econ. Political Weekly, 22(39):A82-A92.

Mathur, A.S., S. Das and S. Sircar (2006). Status of Agriculture in India: Trends and Prospects. Econ. Political Weekly, 41: 5327-5336.

Mehra, S. (1981). Instability in Indian Agriculture in the Context of New Technology. International Food Policy Research Institute, India, Pages: 55. 
Rao, C.H.H. (1975). Technological Change and the Distribution of Gains in Indian Agriculture. MacMillan, New Delhi, India.

Rbi (2010). Handbook of Statistics on State Government Finances. Reserve Bank of India, India.

Sawant, S.D. and C.V. Achuthan (1995). Agricultural Growth Across Crops and Regions: Emerging Trends and Patterns. Econ. Political Weekly, 30:A2-A13.

Tiffin, R. and X. Irz (2006). Is Agriculture the Engine of Growth? Agricultural Economics, 35(1):79-89.

Yang, D.T. and X. Zhu (2004). Modernization of Agriculture and Long-run Growth. Preliminary and Incomplete Notes. 